\title{
Formação de professores de geografia no Brasil: considerações sobre políticas de formação docente e currículo escolari
}

\author{
Geographic teacher training in Brazil: considerations on teaching policies \\ and school curriculum
}

\author{
Natália Lampert Batista'; Cesar De David"; Tascieli Feltrin"'I
}

\section{RESUMO}

Pensar a formação docente, tanto inicial como continuada, é essencial na contemporaneidade. Além disso, compreender como se dá a articulação dessa formação com os currículos escolares se torna urgente e imprescindível. Por isso, tem-se por objetivo deste trabalho refletir sobre a articulação entre políticas de formação inicial docente (Programa Institucional de Bolsas de Iniciação à Docência e Residência Pedagógica) e de formação continuada de professores com o documento norteador da educação básica no país (Base Nacional Comum Curricular). Como fundamento metodológico, emprega-se a revisão bibliográfica sobre as principais políticas públicas educacionais vigentes tanto no âmbito da educação básica quanto no campo da formação de professores. Percebe-se que existe uma tendência de articulação entre o que vem sendo pensado enquanto política de formação, especialmente, a nível inicial, com a Base Nacional Comum Curricular. Por outro lado, a orientação curricular produz um esvaziamento de muitos temas ligados a Geografia e isso deve ser questionado durante os processos de formação docente. Logo, essa dialética entre formação docente e currículo escolar se mostra complexa e justifica a demanda de estudos na busca por compreendê-la.

Palavras-chave: Formação inicial; formação continuada; Currículo; Geografia.

\section{ABSTRACT}

Thinking about teacher education, both initial and continuing, is essential in contemporary times. In addition, understanding how this training is articulated with school curricula becomes urgent and indispensable. Therefore, the objective of this research is to reflect on the articulation between policies of initial teacher education (Programa Institucional de Bolsas de Iniciação à Docência e Residência Pedagógica) and continuing education of teachers with the guiding document of basic education in the country (Base Nacional Comum Curricular). As a methodological foundation, a bibliographical review is used on the main educational public policies in force both in the field of basic education and in the field of teacher education. It is noticed that there is a tendency of articulation between what has been thought of as a training policy, especially at the initial level, with the Common National Curriculum Base. On the other hand, curriculum orientation produces an exhaustion of many geography-related issues and this should be questioned during teacher education processes. Thus, this dialectic between teacher education and school curriculum is complex and justifies the demand for studies in the search to understand it.

Keywords: Initial formation; continuing education; Curriculum; Geography.

'Profa. Pós-doutoranda em Geografia - UFSM E-mail: natilbatista3@gmail.com ORCID: http://orcid.org/0000-0002-1884-2340

"Prof. PhD. do Programa de Pós-graduação em Geografia - UFSM E-mail: Cdedavid2009@gmail.com ORCID: http://orcid.org/0000-00030872-9181

I'Profa. Doutoranda em Educação - UFSM E-mail: tascifeltrin@gmail.com ORCID: http://orcid.org/0000-0002-4018-6749 


\section{INTRODUÇÃO}

Quando pensamos a formação de professores no Brasil precisamos, imprescindivelmente, refletir sobre as políticas educacionais que permeiam essa formação, assim como a forma que essa formação se articula com os currículos escolares. A formação de professores deve emergir das necessidades cotidianas para sua atuação em sala de aula, deve ir além da formação para o trabalho. É fundamental pensar e desenvolver uma formação docente que conduza a constituição de um profissional crítico, reflexivo, questionador das suas próprias condições de trabalho, capaz de auto avaliar a sua prática e de desenvolver coerentemente o currículo escolar, de transformar seu cotidiano e de se posicionar como um ser pensante e socialmente atuante.

A formação de professores perpassa pela articulação entre os conhecimentos específicos da área de atuação, dos conhecimentos pedagógicos e teorias da aprendizagem e sobre o contexto de atuação, isto é, a realidade da profissão de professor na contemporaneidade (NÓVOA, 2016). Entre os elementos fundamentais que encontramos na realidade docente emerge a questão curricular e muitos questionamentos como: Os currículos e as formações iniciais e continuadas dão conta da demanda multicultural da escola? A Base Nacional Comum Curricularii (BNCC) é realmente articulada com o que se pretende com uma educação cidadã para os alunos brasileiros? Programas como o Residência Pedagógica (RP) e o Programa Institucional de Bolsas de Iniciação à Docência (PIBID) dão conta de articular uma formação inicial para o trabalho e a consciência docente crítica?

Essas e muitas outras questões nos inquietam e nos instigam a refletir sobre a articulação entre políticas de formação docente com a orientação curricular da BNCC. Neste artigo, nos dedicamos à abordagem das interfaces entre a formação de professores, tanto em âmbito inicial como continuado, com o currículo mínimo nacional. As discussões aqui tecidas têm como foco a formação de professores no Brasil, pois entendemos que o ensino de Geografia e a educação geográfica ${ }^{i i i}$ têm 
implicações (in)diretas nas dinâmicas territoriais e ambientais as quais precisam ser compreendidas em profundidade pela Geografia.

Portanto, as inquietações e os questionamentos no que tange às políticas públicas de formação docente e a articulação das mesmas com os currículos escolares de Geografia permeiam nossas trajetórias contemporâneas e buscam pensar a escola, o docente e sua formação, o currículo e as implicações dessa complexa relação no processo de ensino-aprendizagem dos estudantes da educação básica. O presente artigo se constitui de uma revisão bibliográfica sobre as principais políticas públicas educacionais vigentes tanto no âmbito da educação básica quanto no campo da formação de professores. Aliamos a essa revisão proposições baseadas na literatura atual e articulamos nossas experiências e vivências profissionais.

Coadunamos às ideias anteriores a percepção de que a formação docente (inicial e continuada) deve preparar esse profissional para uma atuação pautada na articulação entre as teorias e a práticas pedagógicas, ou seja, uma atuação pautada na práxis educacional e, portanto, precisamos de uma efetiva formação docente para construir um profissional efetivamente engajado com a sua atuação e com as suas responsabilidades sociais. "O caminho de uma ação docente que contemple a indissociabilidade entre teoria e prática requer, portanto, uma reforma no modo de conceber, organizar e processar o pensamento e o conhecimento" (MARTINAZZO; BERSCH, 2016, p. 175), isto é, requer um olhar integrado e complexo ${ }^{i v}$ sobre a realidade educacional do território de análise e de aplicação das políticas de formação e das políticas curriculares. Portanto, consideramos que esse debate é multifatorial e carece de abordagens que ultrapassem a leitura do cotidiano escolar de forma ingênua, desarticulada e pautada na mera culpabilização docente frente à realidade vigente no Brasil

A escola hoje tem seu papel questionado e precisa desmistificar sua função, bem como se tornar um espaço de socialização e de construção efetiva de conhecimentos, ultrapassando a mera operacionalização dos conteúdos programáticos e a soma de avaliações paliativas para simplesmente "distribuir notas aos estudantes". Urge que a escola dê conta de trabalhar as temáticas educacionais 
de forma que contribuam para a formação cidadã dos estudantes e isso passa por uma formação docente consciente que consiga ultrapassar a visão sobre si mesmo enquanto mero "ministrante de aulas" e passe a entender o complexo amálgama formado pelos cotidianos escolares. Muitas "[...] cobranças incidem de uma forma mais contundente sobre como a escola está desempenhando sua tarefa" (MARTINAZZO, 2016, p. 149) e, por isso, pensar a escola, o ensino de Geografia e a educação geográfica se torna imprescindível para compreender as novas relações sociais que se estabelecem e as dinâmicas espaciais que se articulam.

Todavia, não é possível compreender a escola sem incorporar as discussões sobre a formação de professores (tanto em âmbito inicial como continuado) e o currículo escolar. É necessário que a formação de professores dê conta de preparar esse profissional para atender às demandas curriculares e para a compreensão efetiva do espaço escolar. Nem só das demandas curriculares se faz a prática, mas, por outro lado, o currículo não pode ser negligenciado. Necessita-se destacar que o currículo é um campo de disputa que, muitas vezes, é meramente "[...] organizado e executado com viés de preparação e de treinamento para o mundo dos serviços, da indústria e dos negócios" (MARTINAZZO, 2016, p. 156).

Então, como pensar a formação de professores para atender às necessidades curriculares sem tornar o docente um mero executor de práticas prontas? Como a formação de professores pode se articular com as demandas do currículo, mas de forma que o professor seja autônomo na sua produção teórico-metodológica frente ao processo de ensino-aprendizagem? Os currículos do ensino de Geografia estão contemplados no trabalho de formação de professores realizados na atualidade?

Reforçamos que pensar a formação de professores de Geografia no Brasil, hoje, passa imprescindivelmente pela abordagem das políticas públicas de formação para docentes e pela nova abordagem curricular proposta pela BNCC. Os atravessamentos entre esses temas precisam ser estreitados de modo que a formação se torne condizente com os conteúdos, habilidades e competências a serem trabalhadas na educação básica pelo professor. 
Por isso, é preciso que compreendamos como se dá a formação de professores no Brasil e como essa formação se articula com as demandas oriundas da BNCC. Todavia, esse caminho deve ser crítico-reflexivo e promover um debate coerente e não simplesmente operacionalizar a aplicação do novo currículo cegamente. A Base e o Novo Ensino Médio passam por inúmeras críticas e debates, eles não se articulam com as proposições de muitos pesquisadores e estudiosos do ensino de Geografia e da educação geográfica. Assim, é preciso pensar uma formação de professores que atenda a demanda dessa normativa, mas sem perder de vista os referenciais da Geografia. É necessário investir em uma formação de professores pensantes, que deem conta de compreender e de aplicar a BNCC da melhor forma possível, mas sem perder de vista os referenciais teórico-metodológicos da Geografia Escolar. Partindo dessas premissas passamos aos eixos de debate e as argumentações teóricas e práticas sobre a temática.

\section{POLÍTICAS DE FORMAÇÃO DOCENTE: OLHARES SOBRE O PIBID, A RESIDÊNCIA PEDAGÓGICA E A FORMAÇÃO CONTINUADA}

A formação inicial docente perpassa por uma série de estratégias didáticopedagógicas e teóricas que instrumentalizarão e embasarão as concepções do profissional docente em começo de carreira. Entretanto, essa formação não é concluída com a entrega do diploma de licenciado. A formação docente ocorre por toda a vida do professor e está vinculada aos desafios e inquietudes que permearão sua atuação profissional.

No Brasil, a formação de professores ocorre por meio de uma formação inicial e, posteriormente, por programas de formação continuada e/ou em serviço, bem como pelas buscas pessoais das docentes frente à autoformaçãov . Segundo a Resolução $n^{\circ} 2$, de $1^{\circ}$ de julho de 2015, que dispõem sobre a formação inicial e continuada docente, destacando que elas devem ocorrer de maneira articulada. O seu artigo $3^{\circ}$ aponta que ambas: 
[...] destinam-se, respectivamente, à preparação e ao desenvolvimento de profissionais para funções de magistério na educação básica em suas etapas educação infantil, ensino fundamental, ensino médio - e modalidades - educação de jovens e adultos, educação especial, educação profissional e técnica de nível médio, educação escolar indígena, educação do campo, educação escolar quilombola e educação à distância - a partir de compreensão ampla e contextualizada de educação e educação escolar, visando assegurar a produção e difusão de conhecimentos de determinada área e a participação na elaboração e implementação do projeto político-pedagógico da instituição, na perspectiva de garantir, com qualidade, os quatro direitos e objetivos de aprendizagem e o seu desenvolvimento, a gestão democrática e a avaliação institucional. (BRASIL, 2015, p. 3).

Assim, a formação inicial e continuada docente tem por perspectiva, ao menos teoricamente, apoiar, instrumentalizar e qualificar a atuação docente em sala de aula, colaborando com a formação de estudantes reflexivos, socialmente atuantes, comprometidos com a sociedade e com o espaço onde vivem. Todavia, é sempre necessário ressaltar que qualidade de ensino não prescinde apenas de capacidades profissionais dos docentes, mas, de modo significativo, de condições de trabalho, de infraestruturas escolares e de valorização da categoria docente.

Como princípios da formação docente, a Resolução, anteriormente mencionada, em seu $\S 5^{\circ}$ destaca que a formação de professores deve ocorrer para todas as etapas e modalidades da educação básica, sendo um compromisso público de Estado e com vistas "à educação de qualidade, construída em bases científicas e técnicas sólidas em consonância com as Diretrizes Curriculares Nacionais para a Educação Básica" (BRASIL, 2015, p. 4), com colaboração de todos os entes federados com as instituições formadoras e os sistemas e redes de ensino e suas instituições. Propõem também que essa formação seja um:

[...] compromisso com projeto social, político e ético que contribua para a consolidação de uma nação soberana, democrática, justa, inclusiva e que promova a emancipação dos indivíduos e grupos sociais, atenta ao reconhecimento e à valorização da diversidade e, portanto, contrária a toda forma de discriminação. (BRASIL, 2015, p. 4).

As Diretrizes Curriculares Nacionais para a Educação Básica (DCNs) e a Resolução $\mathrm{n}^{\circ} 2$ propõe como outro princípio o padrão de qualidade dos cursos de formação de docentes, bem como "a articulação entre a teoria e a prática no processo de formação docente, fundada no domínio dos conhecimentos científicos e didáticos, 
contemplando a indissociabilidade entre ensino, pesquisa e extensão" (BRASIL, 2015, p. 4), sob uma sólida base teórica e interdisciplinar, com equidade no acesso à formação inicial e continuada. Além disso, ressalta "[...] a compreensão da formação continuada como componente essencial da profissionalização inspirada nos diferentes saberes e na experiência docente, integrando-a ao cotidiano da instituição educativa, bem como ao projeto pedagógico" (BRASIL, 2015, p. 5).

Portanto, percebe-se que há uma busca por uma visão que articule a formação docente por todas as etapas e momentos da atuação do profissional docente. 0 professor, sendo um ser humano incompleto e constantemente inacabado, precisa estar em constante formação e constituição do seu saber docente. Todavia, todos os processos de formação devem partir das reais necessidades escolares, dos desafios e inquietações desses docentes com base em conhecimentos técnicos, científicos e, sobretudo, de contexto social e multicultural sobre a diversidade de perspectivas de ação docente, tendo em vista os múltiplos territórios e territorialidades existentes no Brasil.

Como estratégias de formação inicial docente que colaboram com tais premissas, mas que também integram a formação continuada e que visam à articulação entre saberes da educação superior e da educação básica, destacam-se o PIBID e o programa RP regulamentados, atualmente, pela Portaria $n^{\circ} 45$, de 12 de março de 2018 (BRASIL, 2018).

"O PIBID tem como base a concepção dialética de práxis, de modo a articular a teoria e a prática, concebidas como indissociáveis na construção do ensinoaprendizagem de seus sujeitos envolvidos" (FREITAS; TERAMATSU; STRAFORINI, 2017, p. 71). O Programa tem como objetivo aprimorar a formação inicial e continuada de professores que se vinculam às práticas escolares desenvolvidas por meio deste programa, seja na condição de iniciação à docência, seja como supervisor, seja como coordenador institucional. Para isso, segundo Freitas, Teramatsu e Straforini (2017) são submetidas à Coordenação de Aperfeiçoamento de Pessoal de Nível Superior (CAPES) projetos e planos de ação para serem desenvolvidos em parceria entre docentes da educação superior, da educação básica e graduandos das diferentes 
licenciaturas como estratégias de formação docente e de qualificação da atuação desses profissionais.

Assim,

[...] o PIBID não surgiu apenas de uma pretensão política do governo federal, que teria percebido a carência de políticas e programas para a formação de professores em nível federal e suas futuras implicações no sistema educacional do país. Mas, também, tem origem em uma discussão no âmbito internacional sobre a qualidade dos professores da educação básica. (FREITAS; TERAMATSU; STRAFORINI, 2017, p. 83).

Essa política apresenta incontáveis discussões que remetem a apresentação dos seus resultados e desafios. O Programa permite articular o conhecimento dos docentes em atuação com os debates acadêmicos que permeiam a formação de professores e, consequentemente, conduz a uma eficiente proposta de práxis pedagógica para formação docente. A inserção dos acadêmicos na escola desde os primeiros semestres da graduação rompe com a distorcida visão sobre o contexto escolar e aprofunda o olhar sobre o campo de atuação dos professores. Porém, não se pode perder de vista que o entendimento da real dimensão do que é ser docente só ocorre após a inserção como profissional e como professor regente efetivo de uma sala de aula.

Por outro lado, no que tange a RP:

\begin{abstract}
A questão da residência na área da Educação não é uma discussão nova no Brasil e tem surgido também sob diferentes nomenclaturas. A primeira discussão surgiu em 2007 com uma proposta do Senador Marco Maciel (DEM/PE) em que admitiu terse inspirado na residência médica, apontando-a como um avanço na formação dessa categoria. Pelo PLS 227/07, a residência educacional teria carga horária mínima de 800 horas e, dois anos após haver sido implementada, passará a se exigir certificado de aprovação para professores dos anos iniciais do ensino fundamental. Tratava-se de uma concepção de modalidade ulterior à formação inicial a qual denominou de Residência Educacional, incluindo para isto uma proposta de alteração ao artigo 65 da LDBEN/96 vi. (SILVA; CRUZ, 2018, p. 230).
\end{abstract}

Neste sentido, o PIBID destina-se aos primeiros contatos com a sala de aula e a RP volta-se para os semestres finais da graduação, tendo em vista o aprofundamento da relação teoria e prática na formação inicial docente, ou seja, para além da vivência pedagógica esses programas pretendem contribuir com uma efetiva formação para a práxis pedagógica dos docentes em formação. A RP "[...] não se limita somente à 
vivência em sala de aula, mas busca constituir uma interação entre pesquisa acadêmica e teoria-prática docente". (SILVA; CRUZ, 2018, p. 236).

Por este ângulo, a RP propõem a realização da inserção da reflexão sistematizada sobre a atuação docente, sob supervisão/orientação de docentes da educação básica e superior. Por outro lado, há uma consistente e ampla crítica vii ao RP produzida por docentes na educação superior na medida em que:

[...] há um interesse explícito no Programa de Residência de induzir a forma e o conteúdo das atividades e reflexões sobre o trabalho docente verticalizados em duas ações: i) vincular as ações de estágio relacionadas as aprendizagens dispostas na BNCC; ii) enfatizar atividades práticas, entendidas como imersão na sala de aula centrando o ato pedagógico no fazer metodológico-curricular [...] Ressaltamos que além de vincular a formação de professores a uma finalidade estritamente pragmática de servir a uma reformulação curricular da Educação Básica, a indução da reformulação do estágio também fere a autonomia universitária. Foi essa autonomia, duramente conquistada, que permitiu o desenvolvimento das universidades em todas as épocas e, a partir do século passado, as erigiu em suporte fundamental de todo sistema científico e tecnológico. (SILVA; CRUZ, 2018, p. 239).

Por outro lado, é imprescindível que a formação inicial docente dê conta de instrumentalizar os profissionais para a implementação dos currículos, sem perder de vista que "o currículo [...] é campo de lutas e disputas que envolvem concepções (políticas, filosóficas, ética, estética, etc.)" (GIROTTO, 2017, p. 422). Por isso, como professores e pesquisadores não podemos ficar alheios a essas discussões e precisamos aprofundá-las e questionar suas fragilidades, pois a formação docente e o currículo da educação básica terão reflexos centrais nas sociedades do futuro.

Então, assim como as mudanças sociais afetam a escola, a escola e seu currículo afetam a sociedade que se quer construir, portanto o tema aqui proposto é extremamente relevante e central à contemporaneidade. Isso, "pressupõe, essencialmente, uma discussão sobre os fundamentos e os objetivos de uma determinada formação. Sem esta discussão, a escolha dos conteúdos, saberes, práticas que passarão a compor um currículo se tornarão vazias, desarticuladas, reprodutoras de conflitos e de ideologias" (GIROTTO, 2017, p. 422).

Assim: 
[...] a formação de professores destaca-se como um tema crucial e de grande importância dentre as políticas públicas para a educação, pois os desafios apresentados à escola exigem do trabalho educativo outro patamar profissional, muito superior ao hoje existente. Além de oferecer uma formação inicial consistente, que no momento atual não apresenta grandes transformações, é preciso proporcionar aos professores oportunidades de formação continuada. Entretanto, a definição de diretrizes para a formação profissional dos professores não depende apenas da identificação das tarefas próprias da educação escolar, depende também, da identificação do lugar que a formação de professores ocupa no conjunto de fatores que interferem na aprendizagem dos seus alunos. (GOMES, 2011, p. 104).

Veiga (2002, p. 86) aponta que "A relação entre formação inicial e continuada, significa integrar, no próprio currículo da formação inicial, professores já atuantes, que desde logo se tornam agentes da formação dos futuros docentes". Essa perspectiva conduz à concepção de uma formação articulada entre formação inicial e continuada, fazendo com que, se pensada corretamente, auxilie intercâmbios de saberes entre futuros docentes e docentes em regência. Tal fato pode contribuir com o processo de autoformação docente, com a superação das lacunas dos sistemas formativos, bem como com a constituição de uma formação docente que de conta dos desafios e das inquietações da realidade escolar. "A formação inicial deve fornecer ao futuro professor uma sólida bagagem nos âmbitos científico, cultural, social, pedagógico para o exercício profissional, ao passo que a formação continuada se centra nas necessidades e situações vividas pelos docentes". (VEIGA, 2002, p.86).

Neste contexto, a formação continuada, segundo a Resolução $n^{\circ} 2$, de $1^{\circ}$ de julho de 2015, dispõem que a formação continuada deve se dar pelo desenvolvimento de atividades formativas e diferentes modalidades de cursosviii envolvem saberes e práticas, em suas diferentes etapas e modalidades da educação:

[...] § $1^{\circ}$ Em consonância com a legislação, a formação continuada envolve: I atividades formativas organizadas pelos sistemas, redes e instituições de educação básica incluindo desenvolvimento de projetos, inovações pedagógicas, entre outros; II - atividades ou cursos de atualização, com carga horária mínima de 20 (vinte) horas e máxima de 80 (oitenta) horas, por atividades formativas diversas, direcionadas à melhoria do exercício do docente; II - atividades ou cursos de extensão, oferecida por atividades formativas diversas, em consonância com o projeto de extensão aprovado pela instituição de educação superior formadora; IV - cursos de aperfeiçoamento, com carga horária mínima de 180 (cento e oitenta) horas, por atividades formativas diversas, em consonância com o projeto pedagógico da instituição de educação superior; $\vee$ - cursos de especialização lato sensu por atividades formativas diversas, em consonância com o projeto 
pedagógico da instituição de educação superior e de acordo com as normas e resoluções do $\mathrm{CNE}_{\text {; }} \mathrm{VI}$ - cursos de mestrado acadêmico ou profissional, por atividades formativas diversas, de acordo com o projeto pedagógico do curso/programa da instituição de educação superior, respeitadas as normas e resoluções do CNE e da Coordenação de Aperfeiçoamento de Pessoal de Nível Superior - Capes; VII - curso de doutorado, por atividades formativas diversas, de acordo com o projeto pedagógico do curso/programa da instituição de educação superior, respeitadas as normas e resoluções do CNE e da Capes. § $2^{\circ} \mathrm{A}$ instituição formadora, em efetiva articulação com o planejamento estratégico do Fórum Estadual Permanente de Apoio à Formação Docente e com os sistemas e redes de ensino e com as instituições de educação básica, definirá no seu projeto institucional as formas de desenvolvimento da formação continuada dos profissionais do magistério da educação básica, articulando-as às políticas de valorização a serem efetivadas pelos sistemas de ensino. (BRASIL, 2015, p. 14).

Assim, percebemos que há claramente interfaces de formação continuada formal, isto é, promovida por cursos institucionais e vinculados às redes de ensino, mas também interfaces de autoformação e de buscas pessoais dos profissionais de educação que devem ser fomentados para a efetiva formação continuada docente. É imprescindível que a formação continuada passe por um trabalho que leve o docente a uma transformação e qualificação de sua prática e, para que isso se dê de modo efetivo, a formação deve responder as inquietações e necessidades do mesmo.

Assim, a formação de professores na contemporaneidade se torna um processo cada vez mais complexo, pois envolve os currículos das licenciaturas e sua flexibilizaçãoix, as políticas de formação inicial e continuada e a compreensão e aprofundamento do entendimento do que se espera da atuação docente na educação básica. Frente a isso,

No caso particular da formação de professores cabe indagar: que professores estão sendo formados, por meio dos currículos atuais, tanto na formação inicial como na formação continuada? Que professores deveriam ser formados? Professores sintonizados com os padrões dominantes ou professores abertos tanto à pluralidade cultural da sociedade mais ampla como à pluralidade de identidades presente no contexto específico em que se desenvolve a prática pedagógica? Professores comprometidos com o arranjo social existente ou professores questionadores e críticos? Professores que aceitam o neoliberalismo como a única saída ou que se dispõem tanto a criticá-lo como a oferecer alternativas a ele? Professores capazes de uma ação pedagógica multiculturalmente orientada? (MOREIRA, 2001, p. 05).

Defendemos, aqui, que a formação inicial e a continuada docente devem proporcionar a constituição de docentes que: sejam capazes de aprofundar os debates postos a sua profissão; capazes de se posicionar criticamente em relação às 
injustiças sociais; se constituam profissionais engajados e conscientes de seu papel, questionadores construtores do seu próprio saber. No que tange à formação de professores de Geografia, em especial, destacamos a necessidade de profissionais comprometidos com o entendimento das categorias de análise dessa ciência (espaço geográfico, paisagem, lugar, região e território) e de sua transposição didática crítica. O professor de Geografia não pode e não deve se abster das discussões sobre a relação sociedade e natureza e do aprofundamento das temáticas que perpassam pela organização do espaço, pois é dessa relação dialética e, também, complexa que nasce a ciência mãe da Geografia Escolar.

A docência em Geografia imprescindivelmente deve estar engajada com as discussões sócio-políticas, econômicas, ambientais, multiculturais que permeiam o objeto de estudo da ciência geográfica e, assim, promover uma formação inicial e continuada docente que dê conta de aproximar esse debate acadêmico do entendimento da organização do espaço onde as escolas de atuação se encontram e, sobretudo, das metodologias de ensino críticas e reflexivas da Geografia Escolar, que são o cerne da formação docente em Geografia, superando a Geografia meramente descritiva e desarticulada dos problemas e demandas socioambientais. É necessário que o professor de geografia tenha acesso a uma formação docente reflexiva, problematizadora, consciente, multicultural, articulada com a realidade de cada canto deste imenso e plural país que é o Brasil. O PIBID, a RP e as formações continuadas para Geografia precisam compreender a fluidez e hibridização desta área do conhecimento para, assim, dar conta de contribuir efetivamente com os docentes dessa disciplina escolar.

\section{A BNCC COMO "CURRÍCULO" NACIONAL: INQUIETAÇÕES}

Quando pensamos a ideia de um currículo mínimo para um país como o Brasil diretamente nos deparamos com o questionamento sobre a diversidade cultural, econômica, ambiental, social, política do nosso país. Como propor um currículo oficial com bases articuladas para um país de dimensões continentais? Como traçar um 
padrão de características de aprendizagem único para o Brasil? O Brasil como os demais países da América do Sul, devido ao seu passado colonial, apresenta uma forte tendência a desvalorizar as suas peculiaridades culturais, tudo aquilo que o difere de um sempre presente padrão estrangeiro. A incorporação de modelos externos à realidade do país, com um nítido caráter colonial, por um lado inviabiliza o desenvolvimento de possibilidade de superação de suas próprias dificuldades e por outro lado depositam sobre a educação o fardo da falha, do insucesso, pois sendo os modelos pensados e advindos para realidades culturais distintas à nossa, sua aplicabilidade aqui já é de antemão fadada ao fracasso.

Nesse sentido, são necessárias iniciativas que considerem o regional, o tipicamente brasileiro, sejam os modos de falar do caboclo, do índio, do negro, da periferia, agora reconhecidos pela BNCC de Língua Portuguesa, por exemplo, como possibilidade de considerar toda a dimensão do território enquanto possibilidade cultural e não mais enquanto espaço dissonante. Claramente, a BNCC se pretende um currículo mínimo para ser trabalhado, apesar de afirmar o contrário, porém a diversidade e as disparidades regionais do Brasil se impõem com um desafio ao que ela propõe e, consequentemente, refletem-se em todas as críticas que a normativa tem recebido desde o início dos debates até seu efetivo chancelamento.

Nesta acepção:

Longe de uma interlocução com os estudos e pesquisas recentes no campo do currículo, é possível ver um abandono ou negligência ao pensamento acumulado no campo quando se refere a currículo na BNCC, a começar pela leitura de que o documento não é currículo, supondo a produção curricular como uma sistematização restrita ao fazer escolar, à definição de conteúdos e objetivos específicos na escola. Ao mesmo tempo em que a BNCC pretende não se apresentar como o currículo a ser adotado de forma homogênea em todo o extenso território nacional brasileiro, há afirmações no próprio documento que acenam para o contrário. [...] O documento é enfático quando diz ser o balizador de elementos decisivos na educação, como na formação de professores, na avaliação e na elaboração de conteúdos educacionais. (CAMILO COSTA; RODRIGUES; STRIBEL, 2019, p. 98-99).

Essa discussão de reestruturação curricular se aproxima às ideias de flexibilização curricular da educação superior, propondo, por exemplo, a flexibilização do Novo Ensino Médio e retirando a obrigatoriedade de disciplinas do currículo como 
a Geografia. Por outro lado, o currículo presente na BNCC se organiza em competências gerais (para todas as áreas do conhecimento) e em competências específicas (para as disciplinas), mas que muitas vezes não seguem uma sequência (tão) lógica frente ao que se considera adequado à abordagem escolar. Martinazzo (2016) reforça essa afirmação ao destacar que, nas últimas décadas, os discursos sobre educação e políticas educacionais:

[...] destacam que a Educação Básica, assim como a superior, para que possa promover o desenvolvimento deve reestruturar as bases curriculares, e, sobretudo, o enfoque operacional dos conteúdos escolares. Nessas políticas públicas, embora nem sempre a sua intencionalidade seja, claramente, revelada, está à ideia de estabelecimento de um ensino organizado em perspectiva pragmática e instrumental, adequado aos novos tempos e de aceleradas mudanças e de tecnologia avançada. E tudo isso para que a escola possa estar em sintonia com o mundo globalizado e, especificamente, com a denominada sociedade do conhecimento (MARTINAZZO, 2016, p. 159).

Ou seja, tem-se como base um ensino mais utilitarista dos conhecimentos escolares, que nem sempre, conduz à formação de alunos atuantes e cidadãos como pressupõem as políticas de formação docente. Embora contraditório, pretende-se formar professores que desenvolvam senso crítico ao mesmo tempo em que se flexibiliza e fragmenta os currículos escolares, conduzindo, muitas vezes, à formação de estudantes com visões fragmentadas e simplistas. Embora as competências gerais previstas na BNCC, sejam bastante complexas e abrangentes, as competências específicas, da Geografia, são empobrecidas e desarticuladas. A Geografia Física não é totalmente contemplada no currículo mínimo, mas pretende-se, por exemplo, que se discutam questões ambientais. Como fazer efetivamente uma discussão articulada e aprofundada das temáticas centrais ao ensino de Geografia se a relação sociedadenatureza, foco da ciência geográfica, é comprometida? Não se pode compreender impacto ambiental, por exemplo, sem as dimensões sociais e naturais da Geografia. Assim, o currículo da BNCC, apesar de trazer elementos e temáticas coerentes para algumas áreas, por outro lado, fragiliza a Geografia e compromete o seu objeto de estudo.

Destarte, precisamos compreender que "toda política curricular é, assim, uma política de constituição de conhecimento escolar" (AZEVEDO; SARMENTO, 2016, p. 02) 
que pode ou não contribuir com determinada área do conhecimento, pode potencializar ou fragilizar as abordagens escolares de determinados temas. Além disso, é preciso ter claro que:

As sucessivas reformas educacionais, os modismos teórico-metodológicos e, sobretudo, os apelos e demandas do campo empresarial precisam ser sempre acompanhados de muita reflexão para que se compreenda o real significado contido neles. Esse modelo de educação está profundamente subordinado aos interesses da nova economia potencializada pelas Tecnologias de Informação e de Comunicação (TIC). (MARTINAZZO, 2016, p. 159).

Azevedo e Sarmento (2016) mencionam que as (re)formulações curriculares necessitam ser

[...] analisadas conforme o contexto de cada época, com o espaço vivido e produzido pela sociedade capitalista, permitindo, assim, organizar e formular conteúdos e conceitos mediante a percepção dos professores sobre o que seja importante para o aprendizado de seu aluno e, principalmente, a concepção de ensino. (AZEVEDO; SARMENTO, 2016, p. 01).

Para Girotto (2017), a BNCC representa um crucial ponto de debate sobre a educação pública que queremos no Brasil do futuro, assim como "[...] para a compreensão dos diferentes interesses e estratégias que atravessam a educação pública brasileira e o ensino de Geografia e, por isso, precisa ser lida a partir da articulação de diferentes escalas espaço-temporais" (GIROTTO, 2017, p. 420-421). Ao pensar o ensino de Geografia, devemos considerar a necessidade de formar pessoas conscientes e comprometidas com as temáticas inerentes à Geografia Escolar e à ciência geográfica e suas especificidades. Portanto, no momento em que currículo de Geografia é fragilizado o próprio pensamento geográfico é fragilizado e precisa se mobilizar em prol da sua manutenção no espaço escolar e na formação de cidadãos críticos, reflexivos e que não sejam facilmente manipuláveis pelos diferentes interesses do capital e dos interesses dominantes que, muitas vezes, entram em choque com os conhecimentos geográficos. O currículo é um campo de disputas. Envolve as diretrizes de trabalho docente e a vida da escola, do aluno e do País. A Geografia não pode se abster desse debate, é necessário perceber o currículo para além de listagens pedagógicas, isto é, 
Há uma tradição de senso comum no Brasil que confunde currículo com documento formal, muitas vezes caracterizado por uma lista de conteúdos e procedimentos a serem seguidos e executados em um determinado intervalo de tempo. Nas últimas décadas, esta tradição que remonta ao ensino enciclopedista na transição do século XIX ao XX tem sido reforçada por políticas curriculares de cunho neoliberal que definem, rigidamente, os conteúdos que devem ser trabalhados por alunos e professores, sem que haja espaço para criação e participação efetiva. (GIROTTO, 2017, p. 421).

Assim, percebemos claramente que a BNCC se apresenta sim como um currículo mínimo nacional que visa direcionar as abordagens realizadas em sala de aula, que valoriza alguns pontos chave das disciplinas escolares, mas exclui outros, sendo carregada de intencionalidades e isenta de neutralidade político-pedagógica. Além do mais:

Na segunda versão da Base Nacional Comum Curricular para o Ensino Médio, divulgada no primeiro semestre de 2018, efetivou-se a suspeita da comunidade educacional: que somente Língua Portuguesa e Matemática permaneceriam como componentes curriculares (disciplinas escolares) obrigatórios nos três anos do Ensino Médio, ficando os demais componentes curriculares (Inglês, Artes, Educação Física, Química, Física, Biologia, Geografia, História, Sociologia e Filosofia) inseridos nas quatro áreas de conhecimento (Linguagens e suas Tecnologias; Matemática e suas Tecnologias; Ciências da Natureza e suas Tecnologias; Ciências Humanas e Sociais Aplicadas). Nossa crítica a esse conjunto de medidas normativas está no processo de fixação de um outro sentido para o conhecimento escolar e, sobretudo, para a própria instituição escolar, à revelia das conquistas educacionais, pedagógicas e disciplinares (ainda que parciais) que nas últimas décadas foram mobilizadas pelos movimentos sociais organizados, pelos sindicatos dos trabalhadores da educação, pelas universidades e pelas diferentes associações profissionais e de pesquisadores. Inúmeras cartas, manifestos e moções foram escritas e publicizadas criticando o retrocesso e as perdas que tais políticas impõem ao sistema educacional brasileiro, às quais esse presente texto também é signatário (STRAFORINI, 2018, P. 175).

Straforini (2018, p. 177-178) ressalta ainda que é preciso evidenciar a importância do ensino de Geografia na contemporaneidade e que as pesquisas nessa área, "ainda que assumindo fundamentações teórico-metodológicas diferentes, têm apresentado nas últimas duas décadas um movimento de convergência em defesa de um ensino-aprendizagem em que se valorizam processos específicos de raciocínio ou de pensamento amparados na própria Geografia". Não basta apenas navegar pelo espaço e utilizar diferentes mídias no ensino, é preciso compreendê-lo e isso só se faz mediado pelo ensino de Geografia e pela construção do raciocínio geográfico (formal e escolar) que tem uma de suas bases assentadas no pensamento espacial. 
Assim, "a defesa pela Geografia enquanto componente curricular obrigatório nas escolas não pode ignorar o protagonismo que as dinâmicas espaciais vêm assumindo no atual estágio de globalização, que se apresenta como técnico, científico e informacional" (STRAFORINI, 2018, p. 178) e, da mesma maneira, nem a grande contribuição dessa componente curricular para a compreensão de mundo pelos estudantes e para a necessidade de sistematização e aprofundamento do raciocínio geográfico.

Mesmo a BNCC apresentando alguns pontos favoráveis no que tange à inserção das múltiplas linguagens em seu contexto, ainda é passível de críticas, pois desconsidera, em especial no Ensino Médio, a importância de compreender o mundo por meio do olhar geográfico escolar para a formação do cidadão na contemporaneidade. Portanto, defendemos que a Geografia deve se fazer presente na escola e deve ser abordada com efetividade na formação inicial e continuada de docentes geográficos para que as suas práticas pedagógicas possam vir a contribuir com a instrumentalização do sujeito para uma atuação autônoma, crítica, reflexiva e efetivamente cidadã (BATISTA, 2019).

\section{POLÍTICAS DE FORMAÇÃO DE GEOGRAFIA E CURRÍCULO ESCOLAR: REFLEXÕES} FINAIS

Pensar as políticas de formação docente em âmbito inicial e continuado e as suas articulações com os currículos vigentes é central e primordial na contemporaneidade. Precisamos nos debruçar sobre esses temas e compreender em profundidade essa relação para que possamos combater o esvaziamento pedagógico em suas diversas dimensões e aprofundar proposições coerentes e integradas sobre esse tema.

Trata-se, também, de pensar currículo e formação de professores em uma sociedade cada vez mais multicultural, em uma sociedade em que a pluralidade de culturas, etnias, religiões, visões de mundo e outras dimensões das identidades infiltram-se, cada vez mais, nos diversos campos da vida contemporânea. A complexidade das relações, tensões e conflitos resultados dos choques entre essas identidades plurais e de suas lutas por afirmação e representação em políticas e práticas sociais extrapola o âmbito da investigação e da reflexão que se desenvolve 
nas universidades. Esse tenso panorama invade o cotidiano, evidencia-se nos noticiários repletos de preconceitos, xenofobia, violência e guerras, nos espaços virtuais, em que crescentemente se veiculam mensagens racistas e discriminatórias, bem como em qualquer espaço em que se mostra a face desumana do ódio, da agressão, da exclusão ou do desprezo ao "outro", percebido e tratado como diferente. (MOREIRA, 2001, p. 03).

Portanto, a articulação entre as políticas de formação docente com o entendimento aprofundado das proposições curriculares se torna eminente e conduz à necessidade de fortalecimento na práxis pedagógica escolar. É urgente formar professores conscientes de seu papel nesta sociedade dinâmica e fluida, bem como profissionais capazes de desenvolver os currículos escolares sob perspectivas emancipatórias e não meramente reprodutivista das competências e habilidades propostas e de metodologias prontas e pensadas para perpetuar um modelo escolar que, talvez, não seja adequado a todos os cantos do Brasil, tendo em vista suas disparidades regionais. Urge criar uma massa docente articulada, que entenda o seu papel social e se posicione frente ao currículo escolar e a sua própria formação, encontrando respostas as suas inquietações e desafios cotidianos.

É esse professor, a meu ver, o mais capaz de desenvolver formas alternativas de pedagogia que privilegiem a luta pela inclusão e formular, como propõe Varejão (2000), um novo sentido para a desgastada noção de cidadania, a partir de currículos que acolham as diferenças identitárias que marcam os indivíduos e os grupos sociais e, ao mesmo tempo, constituam espaços em que se ensinem e aprendam os conhecimentos e as habilidades necessárias à transformação das relações de poder que socialmente produzem e preservam tais diferenças. É esse professor e são esses currículos que se fazem indispensáveis nas escolas e salas de aula das sociedades multiculturais contemporâneas, tão marcadas pelos efeitos letais do neoliberalismo e de um processo de globalização excludente, evidentes no estado de angústia, desespero, desesperança, ódio, medo e violência que prevalece em todos os grupos cujas vozes vêm sendo silenciadas e cujos direitos vêm sendo flagrantemente desrespeitados. (MOREIRA, 2001, p. 12).

Que esse debate seja capaz de contribuir para a construção de caminhos consistentes de formação e autoformação docente, constituindo a força motriz de um pensamento autônomo no sentido do educador(a) pensar e produzir sua própria caminhada docente, com autonomia formativa e responsabilidade social. A reflexão sobre a educação, a formação de professores, os currículos escolares e o ensino de Geografia se encontram na dialética das relações e se articulam na produção de um país socialmente justo, a partir da construção de conhecimentos, saberes e práticas 
coerentes e necessários à promoção e (re)valorização dos professores, da escola e da própria Geografia escolar.

\section{REFERÊNCIAS}

AZEVEDO, A. C. F; SACRAMENTO, A. C. R. O currículo Mínimo de Geografia frente às políticas curriculares nacionais. In: XVIII Encontro Nacional de Geógrafos - A construção do Brasil: geografia, ação política e democracia, São Luís / MA, Anais. São Luís: AGB, 2016.

BATISTA, N. L. Cartografia Escolar, Multimodalidade e Multiletramentos para o ensino de Geografia na Contemporaneidade. 181 páginas. (Tese de Doutorado). Programa de Pós-Graduação em Geografia. Santa Maria: Universidade Federal de Santa Maria, 2019.

BATISTA, N. L; FELTRIN, T; BECKER, E. L. S. Autoformação docente e formação continuada: olhares autobiográficos sobre a formação de professores da educação básica. In: SOEIRA, E. R; BRASILEIRO, R. M. O. (Org.). Formação de professores para a educação básica: inovações, desafios e tensões. Rio de Janeiro: Dictio Brasil, 2019, p. 188-221.

BRASIL. Resolução $\mathbf{n}^{\circ} \mathbf{2}$, de $\mathbf{1}^{\circ}$ de julho de 2015. Define as Diretrizes Curriculares Nacionais para a formação inicial em nível superior (cursos de licenciatura, cursos de formação pedagógica para graduados e cursos de segunda licenciatura) e para a formação continuada. Brasília: Ministério da Educação, 2015.

BRASIL. Portaria n 45, de 12 de março de 2018. Dispõe sobre a concessão de bolsas e o regime de colaboração no Programa de Residência Pedagógica e no Programa Institucional de Bolsa de Iniciação à Docência (Pibid). Brasília: Ministério da Educação, 2018.

CAMILO COSTA, H; FLOREZ, P; STRIBEL, G. P. Teoria Curricular e a Geografia: convites à reflexão sobre a BNCC. Revista Brasileira de Educação em Geografia, v. 9, p. 86-108, 2019.

FREITAS, A. S. F; TERAMATSU, G; STRAFORINI, R. As dimensões territorial e política do Programa Institucional de Bolsa de Iniciação à Docência (PIBID). Revista Terra Livre, v. 1, p. 75-113, 2017.

GIROTTO, E. D. Entre o abstracionismo pedagógico e os territórios de luta: a base nacional comum curricular e a defesa da escola pública. Horizontes (EDUSF), v. 36, p. 16-30, 2018.

GIROTTO, E. D. Dos PCNs à BNCC: o ensino de geografia sob o domínio neoliberal. GEO UERJ, v. 1, p. 419-439, 2017.

GOMES, M. R. C. Formação de Professores em Contexto Atual. Revista de Educação (Itatiba), v. 14, p. 103-125, 2011. 
MARTINAZZO, C. O desafio curricular do ensino por disciplinas na sociedade do conhecimento. In: MARTINAZZO, C; BARBOSA, M. G; DRESCH, O. I. A educação escolar em um mundo complexo multicultural. Ijuí/RS: Unijuí, 2016, p.147-166.

MARTINAZZO, C; DRESCH, O. I. Reflexões sobre saber-fazer docente na contemporaneidade. In: MARTINAZZO, C; BARBOSA, M. G; DRESCH, O. I. A educação escolar em um mundo complexo multicultural. ljuí/RS: Unijuí, 2016, p.173-190. MOREIRA, A. F. B. Currículo, cultura e formação de professores. Educar em Revista, Curitiba, v. 17, n.0, p. 39-52, 2001.

NóvOA, A. Entrevista com Antonio Nóvoa. In: Revista Nova Escola. 2016. Disponível em http://novaescola.org.br/conteudo/179/entrevista-formacao-antonionovoa. Acessado em setembro de 2016.

PIRES, L. M;CAVALCANTI, L. S. Flexibilização como princípio curricular da formação de professores de geografia. Revista Brasileira de Educação em Geografia, v. 8, p. 63-86, 2018.

REGO, N; COSTELLA, R. Educação geográfica e ensino de geografia, distinções e relações em busca de estranhamentos. Signos Geográficos, v. 1, n. 1, p. 1-15, 2019.

SILVA, K. A. P. C; CRUZ, S. P. S. A Residência Pedagógica na formação de professores: história, hegemonia e resistências. Revista Momento: diálogos em Educação, v. 27, p. 227, 2018.

STRAFORINI, R. O Ensino de Geografia como Prática Espacial de Significação. Estudos Avançados, v. 32, p. 175-195, 2018

VEIGA, I. P. A. Professor: tecnólogo de ensino ou agente social. In: VEIGA, I. P. A. (Org.). Formação de professores: políticas e debates. Campinas, SP: Vozes, 2002.

'O presente artigo é um dos recortes teóricos que integram o projeto "A formação inicial e continuada de professores de Geografia nos países do Cone Sul", desenvolvido no Grupo de Pesquisas Educação e Território (GPET), como proposta de pós-doutorado da primeira autora, no Programa de Pós-graduação em Geografia (PPGGEO), da Universidade Federal de Santa Maria. "O presente trabalho foi realizado com apoio da Coordenação de Aperfeiçoamento de Pessoal de Nível Superior - Brasil (CAPES) - Programa Nacional de Pós-doutorado (PNPD)".

ii“A aspiração do texto, que rejeita assumir a nomenclatura de currículo, é promover a padronização, em alguma medida, dos currículos escolares, estabelecendo as habilidades que os estudantes devem desenvolver em cada ano de ensino. Por essa via também reduz a pluralidade educacional em um país com proporções continentais à 'fragmentação das políticas educacionais', algo que se propõe superar". (CAMILO COSTA; RODRIGUES; STRIBEL, 2019, p. 96). Não se propõem a BNCC com a denominação de currículo, mas na prática ela é um currículo mínimo a ser seguido pelas escolas.

iiiRego e Costella(2019) em seu texto "Educação geográfica e ensino de geografia, distinções e relações em busca de estranhamentos" abordam claramente a distinção entre ensino de Geografia e educação geográfica. Esses conceitos não devem ser confundidos, sob pena de enfraquecer uma importante e significativa discussão da Geografia Escolar. 
iv"Complexo não é sinônimo de complicado. Complexo é referente a algo tecido junto com outro algo, ligado. O simplismo costuma gerar distorções separando o inseparável e, assim, forja complicações. O complexo, ao compreender relacionando o que o reducionismo separa, pode ver o mundo de outro modo e, assim, tornar mais simples o encontro de soluções para o que foi deixado complicado" (REGO; COSTELLA 2019, p. 13).

v Entendemos que "a autoformação docente pressupõe um processo de busca por conhecimentos e estratégias pedagógicas que visem responder as inquietações próprias do professor a partir dos desafios que ele encontra durante a sua trajetória profissional e pessoal, por meio das vivências e experiências cotidianas, com base nas necessidades formativas e em suas concepções ideológicas, epistemológicas e metodológicas construídas por meio da reflexão sobre a práxis pedagógica; A formação continuada pressupõe a busca pelo docente e o estímulo externos por gestores, por exemplo, e demais envolvidos no processo pedagógico, para a construção de novos conhecimentos. Ela pode se dar a partir de capacitações e instrumentalizações docente ou por uma formação voltada para a formação, isto é, a reflexão sobre a práxis profissional". (BATISTA; FELTIN; BECKER, 2019, p.216-217).

viNa proposta original da RP, há características semelhantes à RP médica como destacam Silva e Cruz (2018): "[...] a residência docente se estabeleceria como uma fase posterior à formação inicial do profissional habilitado para atuar na docência da educação básica, no primeiro projeto de modo obrigatório para o ingresso na carreira e nos demais como forma pontuação nos concursos e também de atualização profissional. A nomenclatura utilizada nos três projetos citados: residência educacional, residência pedagógica e residência docente e a forma que são apresentados mostram o campo de fragilidade teóricometodológico e pouco aprofundamento sobre a perspectiva do conceito. Vinculam a residência ao formato da experiência da formação médica. como programa de formação continuada, sem adentrar nas especificidades da formação docente". (SILVA, CRUZ, 2018, p. 232). Porém, isso não ocorre no projeto implementado pela resolução da Portaria n 45, de 12 de março de 2018 (BRASIL, 2018).

vii“ “...] outro elemento de análise que crítica a Residência Pedagógica é a vinculação da prática docente do residente à Base Nacional Comum Curricular - BNCC, algo que nos parece indicar que o programa apresenta como formação inicial (licenciados) e continuada (preceptores) uma aprendizagem do conteúdo e aplicação do conteúdo da educação básica relacionada à BNCC, sendo um dos objetivos centrais do programa característica também minimalista de formação". (SILVA, CRUZ, 2018, p. 239).

viiiCurso de atualização, extensão, aperfeiçoamento, especialização, mestrado e doutorado.

ix"A ideia de flexibilização se associa com a valorização de percursos diferenciados de aprendizagem, tendo em vista a diversificação de espaços (onde), de tempos (quando) e de organização curricular (como), resultantes de processos de autonomização na composição curricular, a partir de suas peculiaridades regionais. Assim caracterizada, grosso modo, a flexibilização pode ser entendida sob duas perspectivas: flexibilização vertical, em que os conteúdos básicos e complementares da ciência de referência deverão ser organizados em torno de uma estrutura vertical; flexibilização horizontal, em que se dá a possibilidade de o aluno participar de várias atividades (científicas, culturais e sociais) e contabilizá-las no seu currículo, para integralização da carga horária mínima exigida para conclusão do curso" (PIRES, CAVALCANTI, 2018, p. 72). 